\title{
A Comparison of the Knowledge of Alzheimer's Disease among Community Pharmacists Based on Regional Practice Setting Using the Alzheimer's Disease Knowledge Scale (ADKS)
}

\author{
Jenna Stearns, PharmD ${ }^{1}$; Rachel Burgoon, PharmD ${ }^{1}$; Zachary Sahadak, PharmD ${ }^{1}$; Beka Alazar, PharmD ${ }^{1}$;
}

Marty L Eng, PharmD, BCGP, BCPP, CDP, CADDCT, FASCP ${ }^{2}$

${ }^{1}$ Cedarville University School of Pharmacy; ${ }^{2}$ Cedarville University School of Pharmacy, Department of Pharmacy Practice

\begin{abstract}
Alzheimer's Disease $(A D)$ is the most prevalent type of dementia and has a high prevalence in the aging population. Due to the requirements for care, it is valuable for members of the healthcare system to be knowledgeable about $A D$ and its treatment. Community pharmacists are particularly valuable in assisting in $A D$ care because of their accessibility to the general public and they are a source for dispensing $A D$ medications. The purpose of this study is to assess the level of knowledge of $A D$ among Ohio community pharmacists based on regional practice settings using the Alzheimer's Disease Knowledge Scale (ADKS). A standardized, 30-question assessment tool known as the Alzheimer's Disease Knowledge Scale exists to measure the level of knowledge of AD among a given population. Studies on $A D$ knowledge have been conducted using this tool, and the use of this scale identifies major misconceptions about $A D$ that could be addressed in education initiatives for both the general public and for health care professionals. This study implemented this tool to compare the knowledge of community pharmacists that serve rural areas to those that serve urban areas. The Ohio Board of Pharmacy provided a list of emails of community pharmacists to send an anonymous survey including both demographic questions and the ADKS. Statistical analyses including independent $t$-tests and descriptive statistics were conducted using SPSS to determine the significance of the data. This study found no statistically significant difference between urban versus rural community pharmacists. However, in the future we hope to identify specific questions that correlate to areas of $A D$ where continuing education may be helpful in improving patient outcomes by enabling caregivers and healthcare providers with a more accurate understanding of $A D$.
\end{abstract}

Keywords: Alzheimer's disease, Knowledge, Community pharmacists, Patients, Rural, Urban

\section{Introduction}

Alzheimer's disease (AD) is the most common form of dementia, composing up to 80 percent of all dementias recognized today and impacting close to 44 million people worldwide. ${ }^{1,3-4}$ It is a progressive neurological disorder ultimately ending in death. ${ }^{1,2} \mathrm{AD}$ affects mostly memory and cognition due to neuronal loss and brain atrophy in the hippocampus and prefrontal cortex. ${ }^{1}$

Loss of perceptual ability and the interpretation of events or words are part of the natural progression of the disease. ${ }^{1}$

The Alzheimer's Disease Knowledge Scale (ADKS) is a standardized tool used to measure knowledge of AD. It is a 30 question assessment tool covering seven primary categories: risk factors, assessment and diagnosis, symptoms, course, life impact, caregiving, and treatment and management. ${ }^{5}$ Studies on $A D$ knowledge have been conducted using this tool on Norwegian psychologists, Australian aging and dementia care professionals, as well as other Australian health professional groups, and college students from University of Northern

Corresponding author: Marty L Eng, PharmD, BCGP, BCPP, CDP, CADDCT, FASCP

Cedarville University School of Pharmacy

Department of Pharmacy

251 N Main Street, Cedarville, OH 45314

Phone: 937-766-4972; Email: martyeng@cedarville.edu lowa. ${ }^{6-9}$ The use of this scale can be used to identify major misconceptions about $A D$ that could potentially be addressed in education initiatives for both the general public and for health care professionals. ${ }^{10}$ Misconceptions include how $A D$ develops, best caregiving practices, public health impact of $A D$, and that $A D$ is a normal part of aging. ${ }^{10}$

Despite the existence of the ADKS since 2009, a 2015 literature review of articles pertaining to knowledge of $A D$ found that there was little consistency in the measurement of Alzheimer's knowledge. ${ }^{11}$ Many researchers developed their own scale to evaluate how much people know about $A D$, which leads us to believe it would be helpful for a standardized tool to be used in evaluating AD knowledge. ${ }^{11}$ Recently, a study was done in Malta using the ADKS (given in English language) that evaluated the knowledge of managing community pharmacists. The average ADKS score was 21.46 out of $30 .{ }^{12}$ They found this to be greater than the knowledge scores of Maltese nurses, but less than those reported in studies on US college students and Norwegian psychologists. ${ }^{12}$ The researchers found that younger pharmacists with less experience actually performed better on the ADKS than their older counterparts. ${ }^{12}$

The high prevalence of AD leads us to believe that it would be valuable for other members of the American healthcare system to be knowledgeable about $A D$ and its treatment. Community pharmacists could be particularly valuable in assisting in $A D$ care because they are widely accessible to the general public and they dispense $A D$ medications. 
We evaluated trends observed in pharmacists from Malta applied to our data to identify a statistically significant difference in the level of knowledge of $A D$ between study groups. This would indicate that current education for pharmacists better equips them for interacting with $A D$ patients. Therefore, our purpose is to see if there is a difference in the level of knowledge of $A D$ between urban or rural community pharmacists. This will allow us to target areas of knowledge that are lacking and identify misconceptions both in the general public and health professionals that could be addressed with future education initiatives. Our end goal of such an education initiative would be to improve patient outcomes by enabling caregivers and healthcare providers with a more accurate understanding of AD.

\section{Methods}

Sample Selection

This cross sectional analysis evaluates a survey that was sent to 4,405 community pharmacists in Ohio to test their AD knowledge. The Ohio Board of Pharmacy was contacted to obtain the emails and zip codes of urban and rural community pharmacists in the state of Ohio. An email was sent with a survey that maintained the anonymity of the participants and included both the Alzheimer's Disease Knowledge Scale (ADKS) as well as specific demographic questions. To classify pharmacists as "urban" or "rural," the United States Department of Agriculture (USDA) and Economic Research Service Rural-Urban Commuting Areas (RUCA) has a classification system utilizing a coded numbering system where numbers 1-3 refer to "urban" and 4-10 refer to "rural."13 Using the latest classification system provided by the USDA and RUCA in 2013, the 88 counties in Ohio were broken down into urban versus rural. ${ }^{14}$ These classifications were used when analyzing data after survey answers were collected.

In order to have a $95 \%$ confidence interval with a $5 \%$ margin of error, there was a required sample of at least 354 survey respondents.

Inclusion criteria referred to community pharmacists in the state of Ohio - both registered pharmacists (RPh) and doctors of pharmacy (PharmD) working full or part time. Exclusion criteria referred to pharmacists in Ohio that do not practice in a community setting and pharmacists working outside of Ohio. Non-probability purposive sampling was used to obtain the sample of pharmacists in Ohio.

\section{Instrumentation and Implementation}

The data was obtained through surveys emailed by an anonymous link to the pharmacists through Qualtrics. The survey included questions from the ADKS as well as demographic information, including age, gender, certification, degree, practice setting, length of time in practice, level of interest in $A D$, family members with $A D$, and frequency of dispensing AD medications. The knowledge level of pharmacists was based upon the ADKS. ${ }^{15}$ The survey consisted of 30 true or false questions that each pharmacist completed. The pharmacist's level of knowledge was based on how many items the pharmacist answered correctly. Previous evaluation found that each of the thirty questions have maintained their validity when compared to current literature. ${ }^{16-61}$

Once the survey was completed, the Cedarville University Institutional Review Board (IRB) approved this study. After IRB approval, the survey was sent to the pharmacists' emails provided by the Board of Pharmacy. The survey was sent out every 2 weeks for four rounds for a total of 8 weeks starting in October of 2017.

Once the survey was officially closed, statistical analysis was conducted through SPSS to determine the level of knowledge of $A D$ amongst community pharmacists. We explored the relationship between urban and rural practice settings as well as age distribution to the knowledge of AD using t-tests.

\section{Results \\ Demographics}

In order to have a $95 \%$ confidence interval with a $5 \%$ margin of error, there was a required sample of at least 354 survey respondents. After our 8 week study timeframe, we had 215 survey responses. Of the 215 responses, only 187 were completed and an additional 13 surveys were excluded due to regional practice setting which left a total of 174 respondents. Our 174 respondents averaged 44 years of age which is demonstrated in Figure 1. In total, 61.5\% were female, 37.4\% were male, and $1.1 \%$ indicated other. Nine pharmacists indicated that they were residency trained and 6 reported board certifications. There were $59.2 \%$ of respondents that practiced in a rural setting and $40.8 \%$ in an urban setting. Additionally, 69.5\% worked at chain pharmacies with $30.5 \%$ working in independent pharmacies. In regards to personal connection to $A D, 65.3 \%$ of the pharmacists reported no personal connection to $A D, 27.2 \%$ had a family member with $A D$, and $7.5 \%$ had a friend with $A D$. The overall mean score was 25.6 points, which correlates to marking $85.3 \%$ of questions correct.

\section{Statistical Analysis}

Primary endpoints for the overall test scores on the ADKS assessment were not statistically significant between rural or urban groups. Rural community pharmacists scored a mean of 25.94 points while urban community pharmacists scored a mean of 25.11 points which correlates with a $p$ value of 0.057 [Figure 3]. There was a slight trend towards rural pharmacists having more knowledge with a difference in average score of 0.83 points. Additionally, no statistical significance was found between length of practice. However, there was a significant difference $(p=0.046)$ between those who indicated $31-35$ years of experience versus those who indicated $15-20$ years of experience. [Figure 2] 
Secondary endpoints included looking at individual questions to find any gaps in knowledge between rural and urban pharmacists. There was a significant difference favoring rural pharmacists $(p=0.017)$ on scale item 19 which assessed the pharmacist's knowledge about tremors in AD. No other individual test items met significance criteria between the rural and urban groups.

Additional analyses indicated no statistical significance in average test scores between independent and chain pharmacists $(p=0.181)$. Unfortunately, there were not enough respondents with residency training or board certifications to calculate if these qualifications correlated to an effect on test scores. There was no significant difference between scores of those who reported having a bachelor's degree compared to those who reported having a doctorate degree $(p=0.614)$. There was no significant difference in test score based on level of interest in AD care $(p=0.052)$ [Figure 4]. However, on average those who stated they were interested scored 1-2 points higher on the assessment than those who indicated they were neutral.

\section{Discussion}

The primary goals of this study were to see if there was a difference in $A D$ knowledge among Ohio pharmacists in rural versus urban settings. When looking at the results, we found there was a slight increase in knowledge of pharmacists who work in a rural setting compared to pharmacists working in an urban setting. Although there was not a statistically significant difference $(p=0.057)$, it was surprising to learn that rural pharmacists seemed to have slightly increased knowledge. However, when looking back on demographic information, there were about $20 \%$ more pharmacists from the rural setting that completed the survey, which may contribute to skewed data. In the future, obtaining normally distributed data and a larger sample size would provide a better indication as to whether or not there is a statistically significant difference.

Originally, it was hypothesized that there would be an increased knowledge amongst younger pharmacists who had just graduated from school. This theory came from a study conducted in Malta where younger pharmacists scored higher than their more experienced counterparts. ${ }^{12}$. The data in this study compared to Malta found that pharmacists who have been practicing 31-35 years actually have more knowledge about Alzheimer's disease than those who have been practicing 15-20 years $(p=0.046)$. However, there were no other significant conclusions relating to practice length. These findings could be contributed to more experience handling $A D$ medications.

In this study, it was shown that Ohio community pharmacists scored an overall mean of 25.6 points on the ADKS survey, while the community pharmacists in Malta had an average score of 21.46 points on the same survey. ${ }^{12}$ The results of the Malta study are comparable to this study and allude to a possible difference in how each country teaches their students about $A D$ in pharmacy school. In another survey determining the level of knowledge of $A D$ in health care staff, participants in the urban setting scored an overall mean of 23.56 points compared with our urban average of 25.11 points; rural health care staff scored the same overall mean of 23.56 points compared with our rural average of $25.94 .^{8}$ This study was not pharmacy specific and included health care workers in all divisions of the care team (nursing, medicine, allied health, and support), so extrapolation to this study is difficult.

\section{Strengths and Limitations}

The most prominent strength of this study included being able to use the previously validated ADKS because it accurately represents knowledge of $A D$ and can be compared with previous literature that employs this scale. The Ohio Board of Pharmacy provided a large amount of data which aided in survey distribution. Qualtrics enabled the sending of multiple survey rounds and filtered out duplicate responses.

The sample size of this study was limited due to the nature of survey research. Many people did not complete the survey and therefore, the sample size was not met. Additionally, there was not a way to control survey response and the data was not evenly distributed.

\section{Future Direction and Clinical Practice}

Pharmacists continue to play a very important role in the management of $A D$ and the hope of this study as it applies to future research is to expand this survey nationwide. With the small survey response, expanding the survey distribution nationwide would allow for more analysis and hopefully statistically significant results. Additionally, a comparison of the knowledge of community pharmacists as compared to other health care professionals could be valuable to determine the distribution of $A D$ knowledge in the healthcare system. The analysis of commonly missed ADKS items from this study could help identify misconceptions that may be addressed to equip community pharmacists with the information to better counsel AD patients, provide support to caregivers and families and have a better baseline knowledge on managing patients with $A D$. A continuing education (CE) course or partnership with pharmacy organizations would be beneficial to disseminate information on current standards in AD knowledge and care.

Acknowledgements: Our group of researchers would like to thank all community pharmacists that participated in our study.

Funding and Conflicts of Interest: The authors received no funding from outside sources and do not have any conflicts of interest. 


\section{References}

1. Martone RL, Piotrowski NA, PhD. Alzheimer's disease. Magill's Medical Guide (Online Edition). 2016.

2. Mendiola-Precoma J, Berumen L, Padilla K, Garcia-Alcocer G. Therapies for Prevention and Treatment of Alzheimer's Disease. Biomed Research International [serial online]. July 28, 2016;2016:1-17. Available from: CINAHL Plus with Full Text, Ipswich, MA. Accessed October 26, 2016.

3. Van Cauwenberghe C, Van Broeckhoven C, Sleegers K. The genetic landscape of Alzheimer disease: clinical implications and perspectives. Genetics in Medicine. 2016;18(5):421430. doi:10.1038/gim.2015.117.

4. About Alzheimer's Disease: Alzheimer's Basics. National Institute on Aging. U.S. Department of Health and Human Services website. https://www.nia.nih.gov/alzheimers/topics/alzheimersbasics. Updated 2016. Accessed September 28, 2016.

5. Carpenter BD, Balsis S, Otilingam PG, Hanson PK, Gatz M. The Alzheimer's Disease Knowledge Scale: Development and Psychometric Properties. The Gerontologist. 2009;49(2):236-247. doi:10.1093/geront/gnp023.

6. Nordhus I, Sivertsen B, Pallesen S. Knowledge about Alzheimer's disease among Norwegian psychologists: The Alzheimer's disease knowledge scale. Aging \& Mental Health. May 2012;16(4):521-528. Available from: CINAHL Plus with Full Text, Ipswich, MA. Accessed September 28, 2016.

7. Bettens G, Ownsworth T, Hohaus L, McKendry Y. Assessing accuracy of knowledge of cognitive effects of normal ageing and mild stage of Alzheimer's disease. Aging \& Mental Health. April 2014;18(3):296-303. Available from: CINAHL Plus with Full Text, Ipswich, MA. Accessed September 28, 2016.

8. Smyth W, Fielding E, Beattie E, Gardner A, Moyle W, Franklin S, Hines S, MacAndrew M. A Survey-Based Study of Knowledge of Alzheimer's Disease Among Health Care Staff. BMC Geriatr. January 2, 2013;13:(2). doi:10.1186/14712318-13-2. Accessed September 28, 2016.

9. Eshbaugh E. Gaps in Alzheimer's Knowledge Among College Students. Educational Gerontology [serial online]. September 2014;40(9):655-665. Available from: Sociological Collection, Ipswich, MA. Accessed September 28, 2016.

10. Lowe D, Balsis S, Hughes M, Shine H, Carpenter B. Misconceptions of Alzheimer's Disease.Clinical Gerontologist [serial online]. March 2015;38(2):149-156. Available from: CINAHL Plus with Full Text, Ipswich, MA. Accessed October 26, 2016.

11. Cahill S, Pierce M, Werner P, Darley A, Bobersky A. A Systematic Review of the Public's Knowledge and Understanding of Alzheimer's Disease and Dementia. Alzheimer Dis Assoc Disord. 2015;29(3):255-275. Accessed September 30, 2016.

12. Zerafa N, Scerri, C. Knowledge and Pharmacological Management of Alzheimer's Disease by Managing Community Pharmacists: A Nationwide Study. International Journal of Clinical Pharmacy. 2016:1-9. Accessed September 30, 2016.

13. United States Department of Agriculture Economic Research Service. Urban Influence Codes Documentation. http://www.ers.usda.gov/data-products/urban-influencecodes/documentation.aspx. May 2013. Updated October 12, 2016. Accessed November 13, 2016.
14. United States Department of Agriculture Economic Research Service. Urban Influence Codes. http://www.ers.usda.gov/data-products/urban-influencecodes.aspx. May 2013. Updated October 12, 2016. Accessed November 13, 2016.

15. Carpenter BD, Balsis S, Otilingam PG, Hanson PK, Gatz M. The Alzheimer's Disease Knowledge Scale: Development and Psychometric Properties. The Gerontologist. 2009;49(2):236-247. doi:10.1093/geront/gnp023.

16. Alzheimer's Association. About depression and Alzheimer's disease fact sheet. 29 June 2005.

17. Small, GW, Robins BPV, Buckholtz PP, et al. Diagnosis and treatment of Alzheimer disease and related disorders: consensus statement of the American Association for Geriatric Psychiatry, the Alzheimer's Association and the American Geriatric Society. Journal of the American Medical Association, 278, 1363-1371.

18. Sun X, Steffens DC, Au R, et al. Amyloid-associated depression. Archives of General Psychiatry. 2008;65(5):542550.

19. Fillit HM, Butler RN, O'Connell AW, et al. Achieving and maintaining cognitive vitality with aging. Mayo Clinic Proceedings. 2002;77:681-696.

20. Morris JC. Dementia update 2005. Alzheimer's Disease and Associated Disorders. 2005;19:100-117.

21. Wilson RS, Mendes de Leon CF, Barnes LL, et al. Participation in cognitively stimulating activities and risk of incident Alzheimer disease. Journal of the American Medical Association. 2002;287:742-748.

22. Alzheimer's Association. About Alzheimer's disease fact sheet. 29 June 2005.

23. Geriatric Mental Health Foundation. Caring for the Alzheimer's disease patient. 28 May 2008.

24. Alzheimer's Association. About agitation and Alzheimer's disease fact sheet. 29 June 2005.

25. Corey-Bloom J, Yaari R, Weisman D. Managing patients with Alzheimer's disease. Practical Neurology. 2006;6:78-89.

26. Hochhalter AK, Overmier JB, Gasper SM, et al. A comparison of spaced retrieval to other schedules of practice for people with dementia. Experimental Aging Research. 2005;31:101-118.

27. Woods RT. Psychological "therapies" in dementia. Psychological problems of aging. John Wiley \& Sons, LTD. 1999:311-344.

28. Alzheimer's Association. Ethical issues in Alzheimer's disease fact sheet: respect for autonomy, care, and patient rights. 3 Oct 2003.

29. Alzheimer's Association. About sleep changes in Alzheimer's disease fact sheet. 29 June 2005.

30. McCurry SM, Gibbons LE, Logsdon RG, et al. Nighttime insomnia treatment and education for Alzheimer's disease: a randomized controlled trial. Journal of the American Geriatric Society. 2005;53(5):793-802.

31. American Psychiatric Association. Diagnostic and statistical manual of mental health disorders (DSM-IV). American Psychiatric Association. 1994.

32. Gintner GG. Differential diagnosis in older adults: dementia, depression and delirium. Journal of Counseling and Development. 1995;73(3):346-351.

33. National Alliance for Caregiving and AARP. Caregiving in the United States. 2004. 
34. Spaccavento S, Del Prete M, Craca A, et al. Influence of nutritional status on cognitive, functional and neuropsychiatric deficits in Alzheimer's disease. Archives of Gerontology and Geriatrics. 2008.

35. Volicer L, Hurley AC. Management of behavioral symptoms in progressive degenerative dementia. Journal of Gerontology: Medical Sciences. 2003;58A:837-845.

36. Licht EA, McMurtray MM, Ronald ES, et al. Cognitive differences between early and late-onset Alzheimer's disease. American Journal of Alzheimer's Disease. 2007;22(3):218-222.

37. Alzheimer's Association. About the stages of Alzheimer's disease fact sheet. 29 June 2005.

38. Austrom MG, Damush TM, Hartwell CW, et al. Development and implementation of nonpharmacologic protocols for the management of patients with Alzheimer's disease and their families in a mutliracial primary care setting. The Gerontologist. 2004;44:548-553.

39. Brody EM, Kleban MH, Moss MS, et al. Predictors of falls among institutionalized women with Alzheimer's disease. Journal of the American Geriatrics Society. 1984;32(12):877-882.

40. Alzheimer's Association. About behavioral and psychiatric Alzheimer symptoms fact sheet. 5 Sept 2005.

41. Beers MH, Berkow R, Bogin RM, et al. The Merck Manual of Geriatrics, 3rd Edition. Merck Research Laboratories. 2000.

42. Sparks DL, Sabbagh MN, Breitner JC, et al. Is cholesterol a culprit in Alzheimer's disease? International Psychogeriatrics. 2003;15:153-159.

43. American Association for Geriatric Psychiatry, the Alzheimer's Association and the American Geriatric Society. Journal of the American Medical Association. 278:13631371.

44. Alzheimer's Association. Action series: steps to getting a diagnosis; finding out if it's Alzheimer's disease. 25 April 2005.

45. Mendez MF, Mastri AR, Sung JH, et al. Neuropathologically confirmed Alzheimer's disease: clinical diagnoses in 394 cases. Journal of Geriatric Psychiatry and Neurology. 1991;4(1):26-29.

46. Caputo M, Monastero R, Mariani E, et al. Neuropsychiatric symptoms in 921 elderly subjects with dementia: a comparison between vascular and neurodegenerative types. Acta Psychiatrica Scandinavica. 2008;117(6):455-464.
47. Karine P. Natural history of decline in instrumental activities of daily living performance over the 10 years preceding the clinical diagnosis of dementia: a prospective populationbased study. Journal of American Geriatrics Society. 2008;56(1):37-44.

48. Alzheimer's Association. About hallucinations fact sheet. 5 Sept 2005.

49. Mace NL, Rabins PV. The 36-hour day, 3rd edition. The Johns Hopkins University Press. 1999.

50. Rao V, Lyketsos CG. Delusions in Alzheimer's disease. The Journal of Neuropsychiatry and Clinical Neuroscience. 1998;10(4):373-382.

51. Grossberg GT, Desai AK. Management of Alzheimer's disease. Journal of Gerontology. 2003;58(4):331-353.

52. Alzheimer's Association. About medication fact sheet. 11 July 2005.

53. Szekly CA, Breitner JC, Zandi PP. Prevention of Alzheimer's disease. International Review of Psychiatry. 2007;16(9):693706.

54. Qiu C, Windblad B, Fratiglioni L. The age-dependent relation of blood pressure to cognitive function and dementia. Lancet Neurology. 2005;4:487-499.

55. Solfrizzi V, Panza F, Colacicco AM, et al. Vascular risk factors, incidence of $\mathrm{MCl}$ and rates of progression to dementia. 2004;63(10):1882-1891.

56. Waring SC, Rosenberg RN. Genome-wide association studies in Alzheimer's disease. Archives of Neurology. 2008;65(3):329-334.

57. Brown LB, Ott BR. Driving and dementia: a review of the literature. Journal of Geriatric Psychiatry and Neurology. 2004;17:232-240.

58. Hunt I. Driving performance in persons with mild senile dementia of the Alzheimer type. Journal of American Geriatric Society. 1993;41:747-753.

59. Shah S, Reichman WE. Treatment of Alzheimer's disease across the spectrum of severity. Clinical Interventions in Aging. 2006;1(2):131-142.

60. Alzheimer's Association. 10 warning signs of AD. 12 Sept 2005.

61. Stopford CL, Snowden JS, Thompson JC, et al. Distinct memory profiles in Alzheimer's disease. Cortex. 2007;43(7):846-857. 


\section{Tables and Figures}

Figure 1. Age frequency of the number of pharmacists who completed the survey

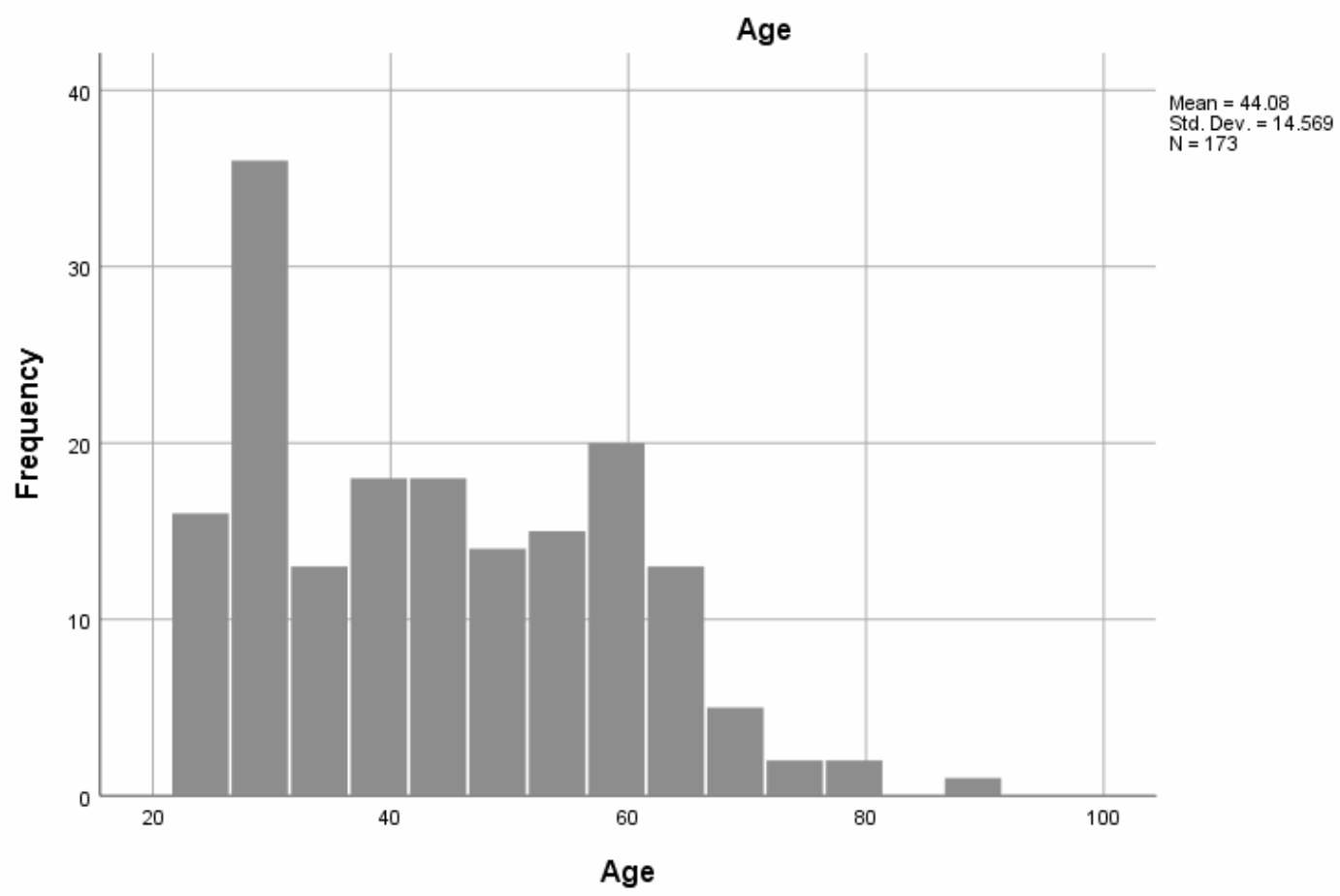

Figure 2. Length of practice (years) compared to mean score on ADKS

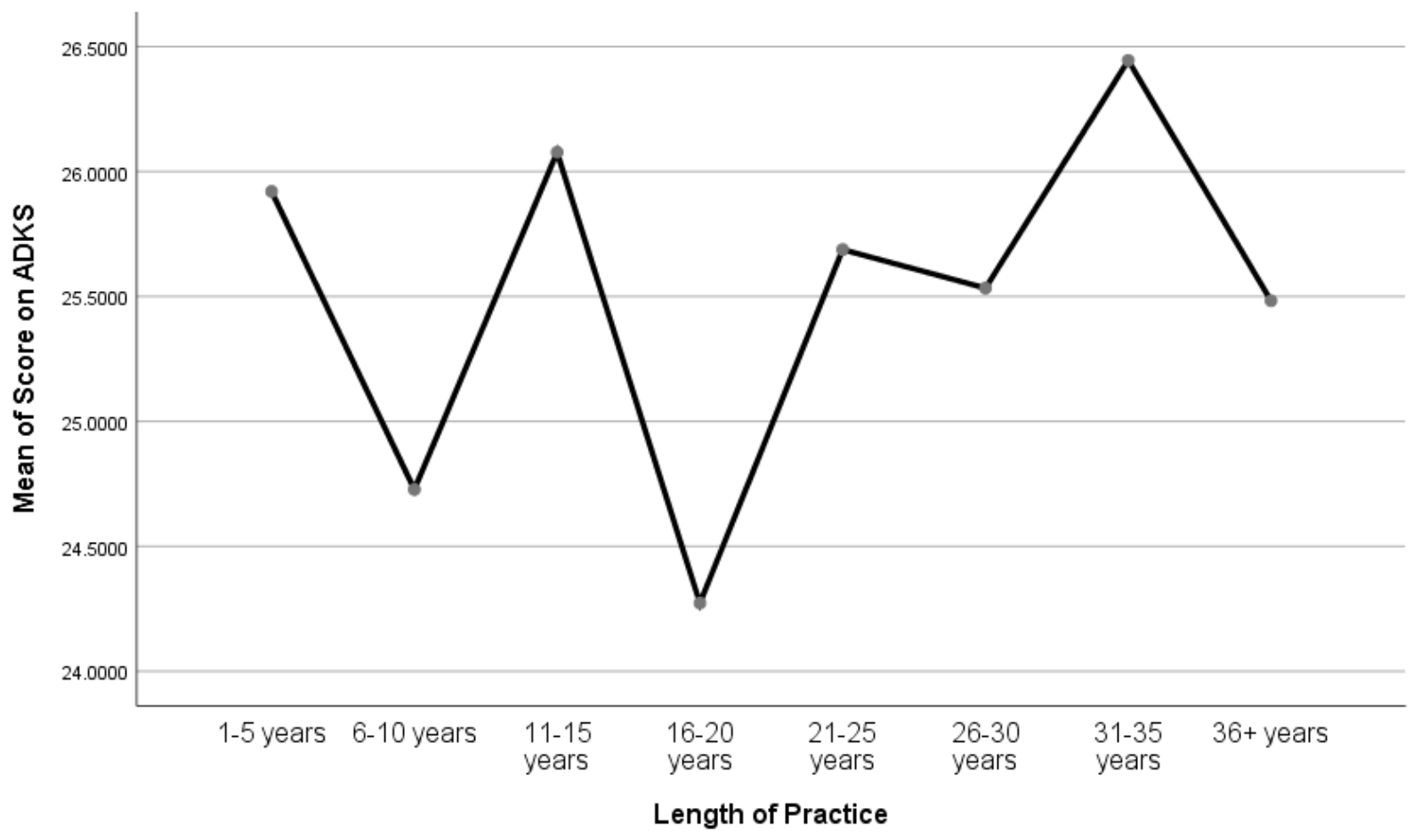


Figure 3. Score on ADKS versus Practice Setting

30

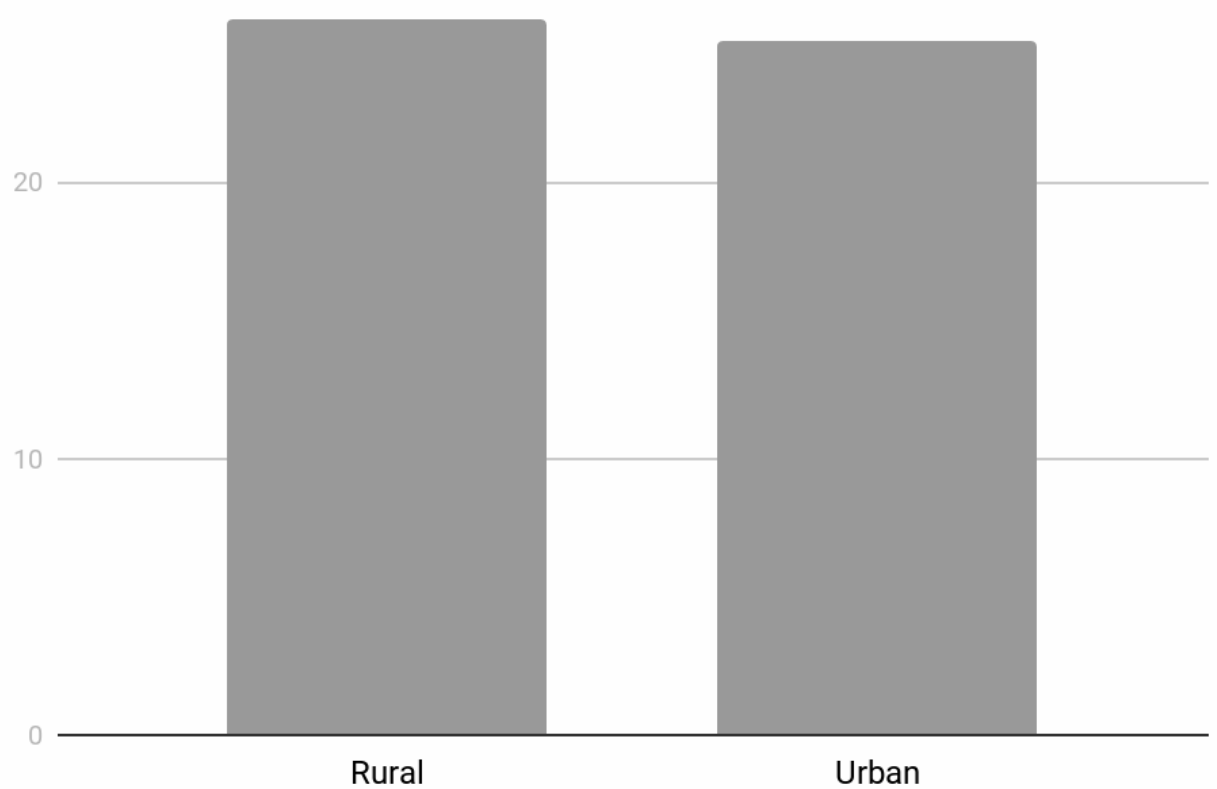

Figure 4. Average Score on ADKS versus Interest Level

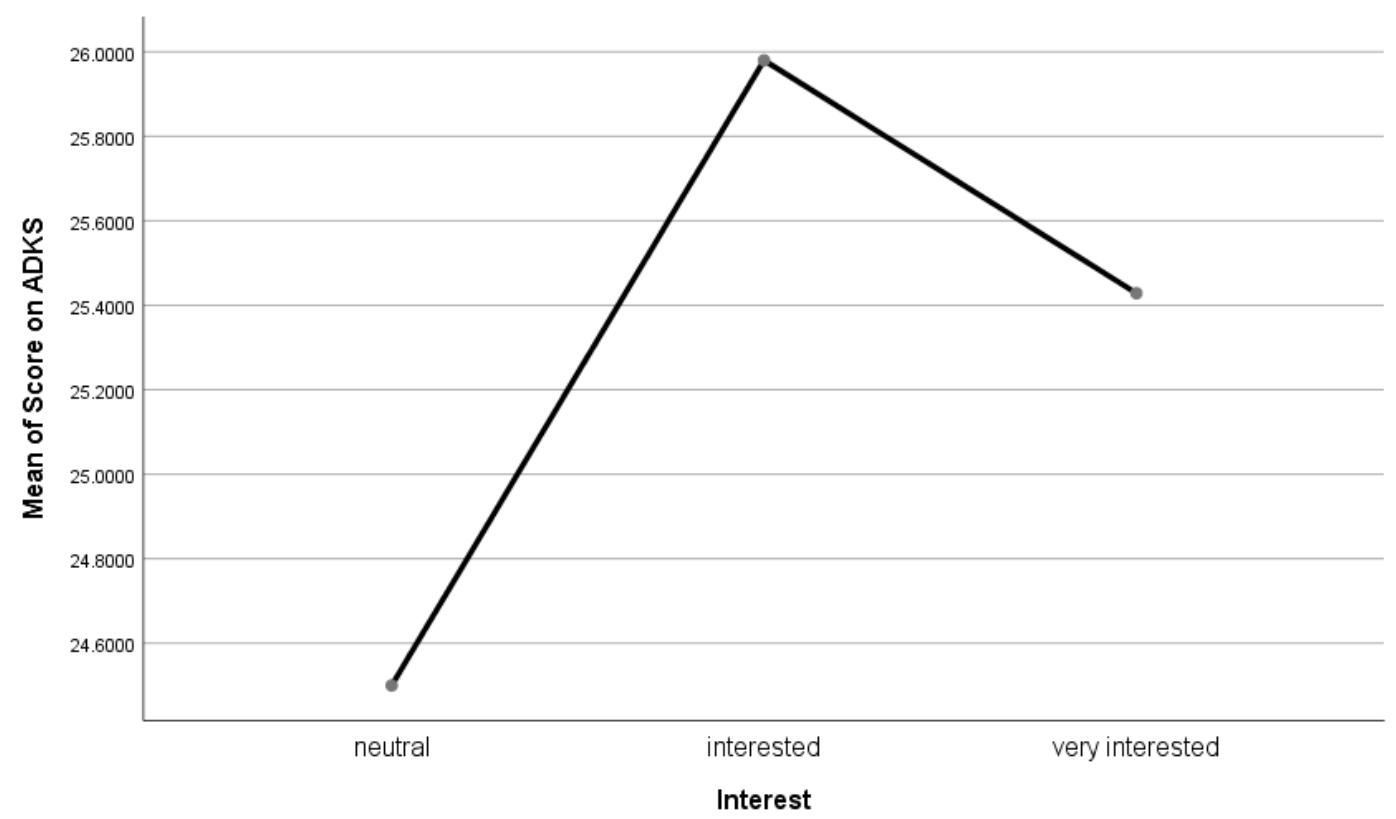

